\title{
Congenital diaphragmatic hernia; masquarding as hydropneumothorax
}

\author{
Yadav RP, ${ }^{1}$ Agrawal C S, ${ }^{1}$ Pathania O P, ${ }^{1}$ Shrestha $\mathrm{P}^{2}$ Sharmal $S,{ }^{3}$ Shrivastaw $\mathrm{M}^{4}$
}

\begin{abstract}
Congenital diaphragmatic hernia occurs in about 1 in 3000 births among which over $90 \%$ of the patients will be diagnosed either antenatally or will present with respiratory distress in the first few hours of life and about $5 \%$ to $30 \%$ of diaphragmatic hernias present beyond the neonatal period. The extent of herniation of abdominal viscera into the thorax may vary, leading to acute or intermittent symptoms. The inappropriate insertion of a chest drain, although relieving the symptoms temporarily, may result in serious consequences by damaging intrathoracic abdominal viscera.
\end{abstract}

Key words : Congenital diaphragmatic hernia, hydropneumothorax.

\section{INTRODUCTION}

Congenital diaphragmatic hernia $(\mathrm{CDH})$ occurs in about 1 in 3000 births. The most common defect is the posterolateral (Bochdalek) type. Over $90 \%$ of the patients will be diagnosed either antenatally or will present with respiratory distress in the first few hours of life. In these cases there are few diagnostic problems. There is a significant mortality associated with this group. ${ }^{1}$ However, about $5 \%$ to $30 \%$ of diaphragmatic hernias present beyond the neonatal period. ${ }^{2}$ Although the mortality in this group is low, the morbidity may be significant. The late presenting congenital diaphragmatic hernia poses considerable diagnostic challenges because of its varied presentation often resulting in diagnostic delay, inappropriate treatment, and potential fatal outcome. ${ }^{3}$ Here we present a case of congenital diaphragmatic hernia in a child presenting at the age of 13 years which was initially misdiagnosed as a case of left sided hydropneumothorax.

Correspondence: Dr. Rohit Prasad Yadav

E-mail: yadavrohitl@yahoo.com

\section{CASE REPORT}

A previously healthy 13 year old boy presented to emergency department of BPKIHS with complaints of pain in chest and abdomen for 5 days and occasional vomiting for same duration.His chest pain used to get aggravated on deep inspiration and he was having continuous dull aching pain in abdomen There was history of trauma on left elbow (fracture of lower end of humerus) due to fall from bicycle 17 days back but no gastrointestinal illness.

On examination he was afebrile, tachycardic, tachypnoeic. Air entry was reduced on the left side chest with mediastinal shift to the right. Abdominal examination was normal. A chest radiograph (fig 1) showed a massive gastrothorax on the left side with mediastinal shift to the right side which was misdiagnosed as hydropneumothorax. He was diagnosed as a case of massive plural effusion probably due to tuberculosis and thoracocentesis was done in emergency and he was admitted in the department of pediatric. The case was 


\section{CASE REPORT}

Vadav RP et al. congenital diaphragmatic

again reviewed by the consultants and re-surgical consultation was asked. He was suspected to have congenital diaphragmatic hernia. A nasogastric tube was inserted which gave symptomatic relief to the patient. Barium meal and Computed tomography of the chest (fig 2,3) demonstrated left sided Bochdalek diaphragmatic hernia with pronounced herniation of the stomach and some parts of colon into the left hemithorax, with contralateral mediastinal shift and complete collapse of the left lung.

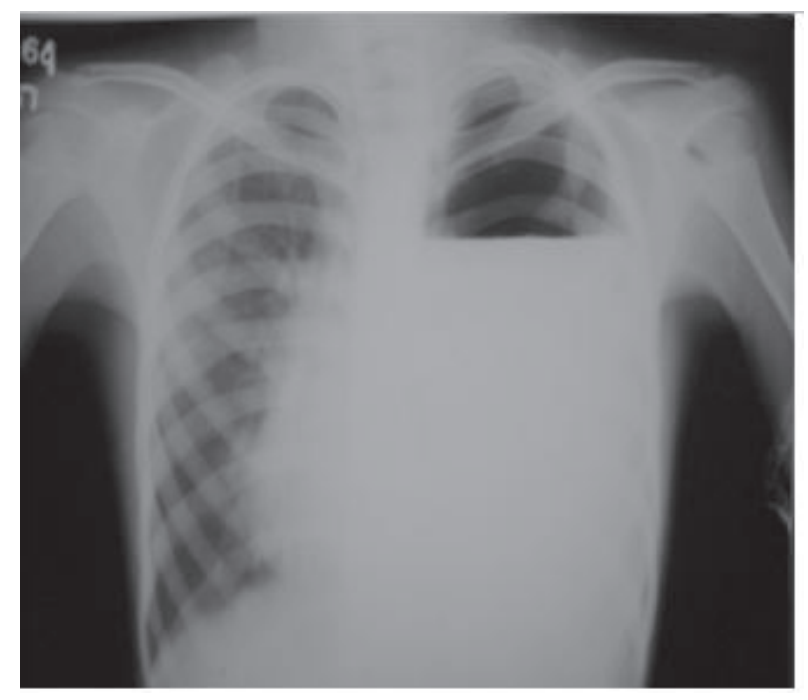

Figure I

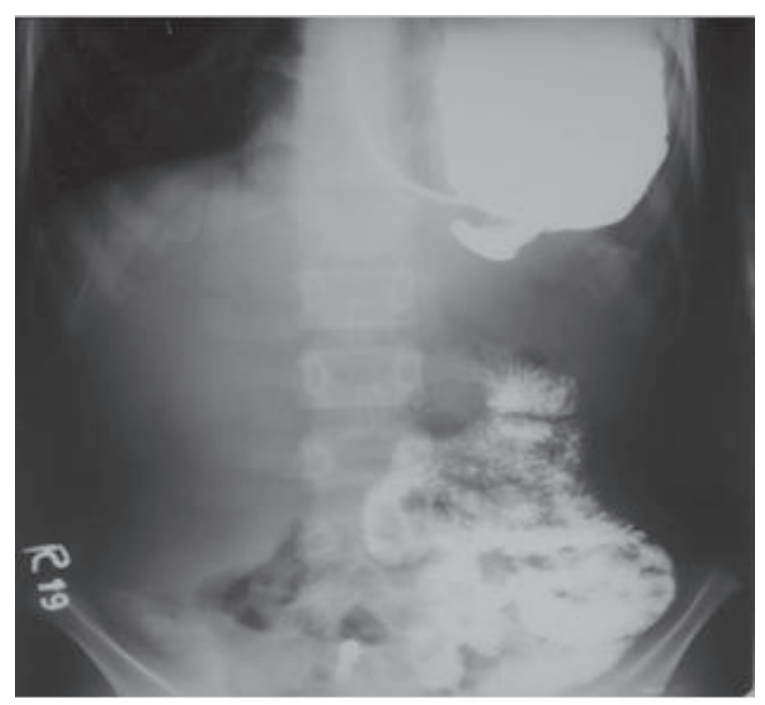

Figure II

\section{DISCUSSION}

In late presenting congenital diaphragmatic hernias, the extent of herniation of abdominal viscera into the thorax may vary, leading to acute or intermittent symptoms. A previously normal chest radiograph has been reported in number of cases suggesting that in such cases the defect is long standing, but the viscera are confined by the hernial sac or obturated by a solid organ. The patient becomes symptomatic when actual herniation takes place later in life because of rupture of the hernial sac. There is probably a second group of patients in whom the herniation has been long standing, but who only present when a complication of the herniated contents such as volvulus or strangulation occurs. ${ }^{3}$ 
Journal of College of Medical Sciences-Nepal, 2013, Vol-9, No-3,

Berman et al in their series of 26 patients with late presenting $\mathrm{CDH}$, reported that 16 patients had a initial diagnosis of primary lung abnormality, with four patients undergoing thoracocentesis. ${ }^{3}$ There are a number of case reports in the literature where late presenting diaphragmatic hernias have been misdiagnosed as pneumothorax and patients have undergone unnecessary emergency thoracocentesis. ${ }^{4-6}$ In our patient although the clinical presentation was suggestive of left sided hydropneumothorax, later on diagnosis of left sided congenital diaphragmatic hernia was considered and confirmed by Barium meal and Computed tomography of the chest, which showed the stomach on the left side of the thorax. The inappropriate insertion of a chest drain, although relieving the symptoms temporarily, may result in serious consequences by damaging intrathoracic abdominal viscera. There is also the risk of spillage of the gastric or intestinal contents into the thoracic cavity leading to mediastinitis. Damage to the spleen or blood vessels in cases of left sided CDH could result in life threatening haemorrhage. In cases of right sided $\mathrm{CDH}$, an intrathoracic liver may be damaged by a chest drain. ${ }^{6}$

If the diagnosis of late presenting $\mathrm{CDH}$ is suspected, an ultrasound is a useful diagnostic tool. ${ }^{7}$ When gastrothorax is suspected, a chest radiograph with a nasogastric tube in place will lead to the correct diagnosis. ${ }^{3}$ The other diagnostic tools available for the accurate diagnosis of late presenting $\mathrm{CDH}$ include computed tomography, magnetic resonance imaging, and upper or lower gastrointestinal contrast studies. ${ }^{7}$

\section{CONCLUSION}

The diagnostic possibility of late presenting congenital diaphragmatic hernia should be considered in unusual cases of pneumothorax, especially in the absence of trauma so that thoracocentesis can be avoided. Nasogastric tube placement must be considered as an early diagnostic or therapeutic intervention when the diagnosis is suspected. A high index of suspicion is required to avoid undue delay in diagnosis and inappropriate management.

\section{REFERENCES}

1. Davenport M, Holmes K. Current management of congenital diaphragmatic hernia. Br J Hosp Med 1995; 53: 95-101.

2. Gleeson F, Spitz L. Pitfalls in the diagnosis of congenital diaphragmatic hernia. Arch Dis Child 1991;66:670-1.

3. Berman L, Stringer D, Ein SH, et al. The late presenting paediatric Bochdalek hernia: a 20-year review. J Pediatr Surg 1988;23:735-9.

4. Fein JA, Loiselle J, Eberlein S, et al. Diaphragmatic hernia masquerading as pneumothorax in two toddlers. Ann Emerg Med 1993;22:1221-4.

5. Snyder HS, Salo DF, Kelly PH. Congenital diaphragmatic hernia presenting as massive gastrothorax. Ann Emerg Med 1990;19:562-4.

6. Coren ME, Rosenthal M, Bush A. Congenital diaphragmatic hernia misdiagnosed as tension pneumothorax. Pediatr Pulmonol 1997;24:119-21.

7. Oh KS, Newman B, Bender TM, et al. Radiological evaluation of the diaphragm. Radiol Clin North Am 1988;26:355-64. 